\title{
Paracardiac lipomatosis in exogenous Cushing's syndrome
}

\author{
L. B. A. VAN DE PUTTE, J. P. M. WAGENAAR, and \\ K WA HIA N S N \\ Departments of Nephrology, Pulmonology, and Radiology, University Hospital, Leiden, \\ The Netherlands
}

\begin{abstract}
van de Putte, L. B. A., Wagenaar, J. P. M., and San, K. H. (1973). Thorax, 28, 653-656. Paracardiac lipomatosis in exogenous Cushing's syndrome. Histologically proven lipomatosis presenting as paracardiac masses on the chest radiograph is described in a patient with a renal graft. This lesion was caused by the prednisone therapy and diminished after lowering the dosage.

Review of 90 renal transplant patients revealed one likely example of this syndrome and four patients had other radiographic abnormalities suggestive of intrathoracic lipomatosis.

It is pointed out that intrathoracic lipomatosis can produce a variety of abnormalities on the chest radiograph and that sometimes these changes need to be differentiated from primary tumours.
\end{abstract}

Deposition of fat in the trunk, face, and neck is a characteristic feature of Cushing's syndrome. Unusual episternal (Lucena, Bennett, and Pierre, 1966) and presacral (Sowerbutts, 1959) fat accumulations have also been recorded. Several recent case reports mention superior mediastinal widening due to lipomatosis in endogenous (Santini and Williams, 1971) and exogenous (Koerner and Sun, 1966; Bodman and Condemi, 1967 ; Price and Rigler, 1970 ; Teates, 1970 ; Fraser and Paré, 1970) Cushing's syndrome. The condition is rare and has sometimes led to surgical exploration.

In addition to mediastinal widening, prominent epicardial fat pads may be another manifestation of intrathoracic lipomatosis (Koerner and Sun, 1966 ; Bodman and Condemi, 1967 ; Price and Rigler, 1970 ; Teates, 1970).

The patient to be reported developed puzzling paracardiac masses whilst receiving corticosteroids after renal transplantation. Subsequent histological examination showed the lesion to be a form of drug-induced lipomatosis. At a later date one likely example of this syndrome was discovered after reviewing all the patients who had undergone renal transplantation.

\section{CASE REPORT}

L. H.-M., a 51-year-old woman, underwent intermittent haemodialysis because of renal insufficiency due to hereditary nephritis. A cadaver renal transplantation was performed in August 1971. Two rejection episodes were treated by high doses of prednisone, up to $150 \mathrm{mg}$ daily, for short periods. Four months after the operation a routine chest radiograph revealed bilateral paracardiac masses (Fig. 1) not present before transplantation (Fig. 2). Superior mediastinal widening and thickening of the thoracic wall were also noted.

Apart from a marked Cushingoid appearance, the physical examination was unremarkable. There was no significant increase in weight compared to the pretransplantation period. Extensive laboratory investigations gave no indication as to the nature of the radiographic abnormalities. Finally, a left thoracoscopy revealed a mass of adipose tissue (Fig. 3). Biopsy showed normal fat tissue covered by a monolayer of flat epithelial cells, presumably the parietal pleura. Over a period of several months. as the dose of prednisone was gradually decreased to $10 \mathrm{mg}$ daily, the Cushingoid appearance and the paracadiac shadow diminished simultaneously.

The above findings then prompted us to examine the available material in our renal transplantation series ( 90 patients), since all the patients wore roceiving 


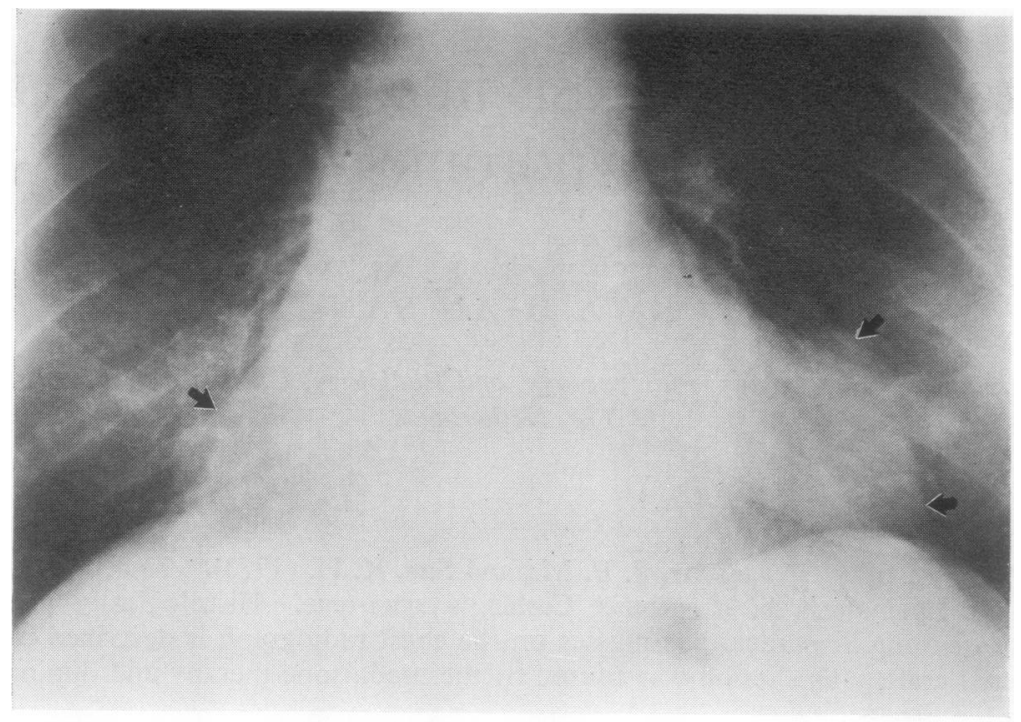

(a)

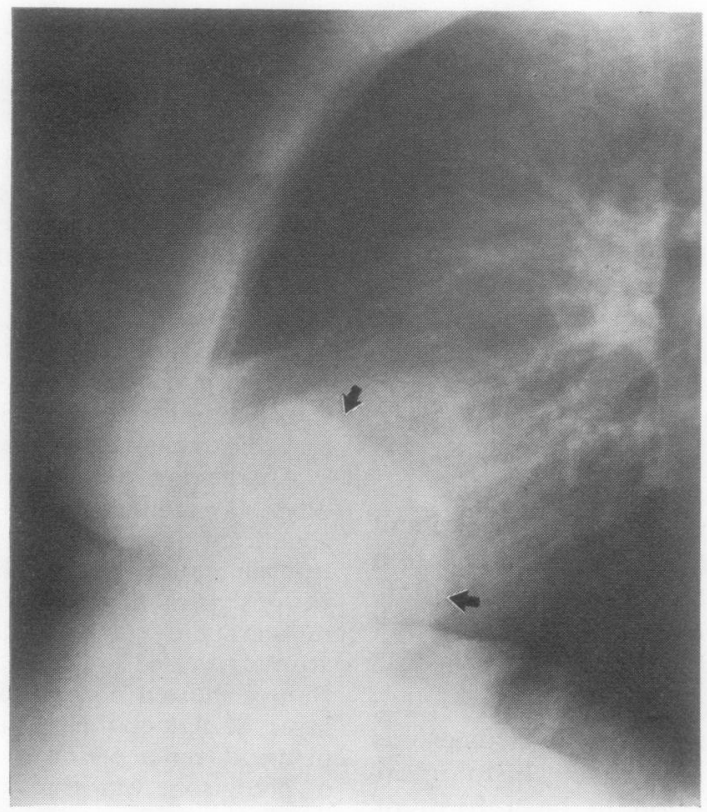

(b)

FIG. 1. Chest radiographs taken four months after transplantation showing the paracardiac masses (arrows) in the posteroanterior (a) and lateral (b) views. 


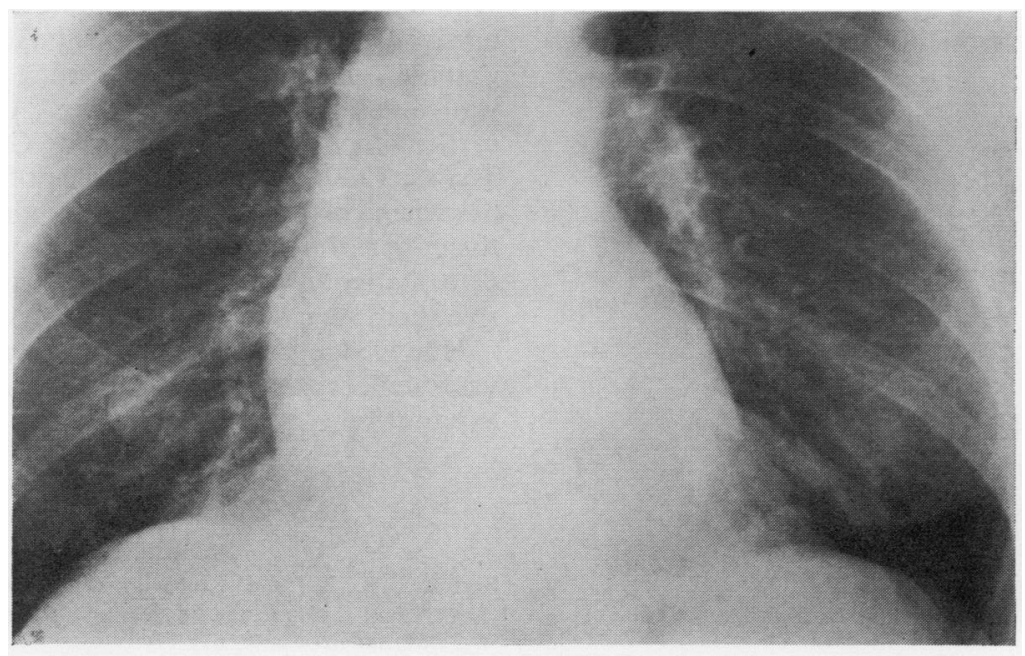

(a)

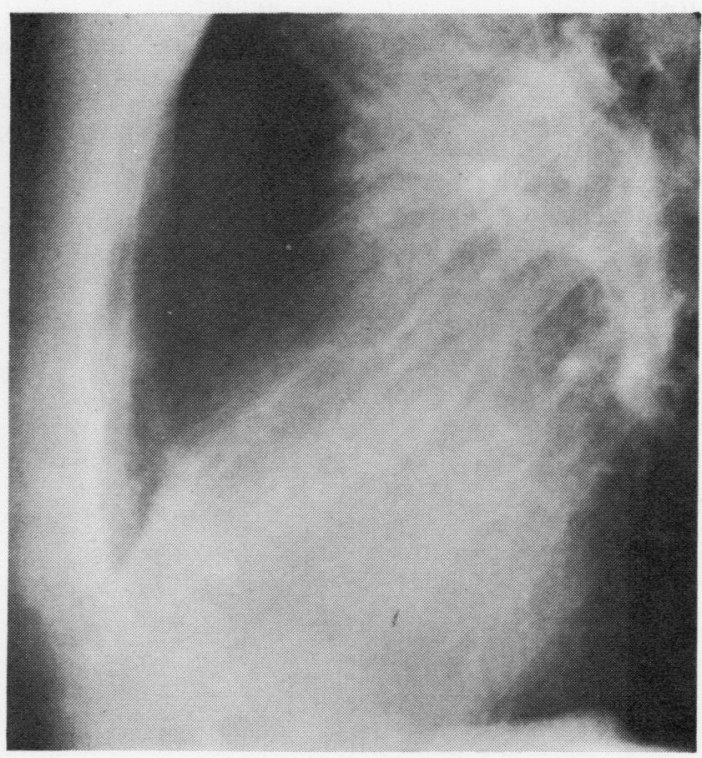

(b)

FIG. 2. Posteroanterior (a) and lateral (b) chest radiographs before transplantation. 


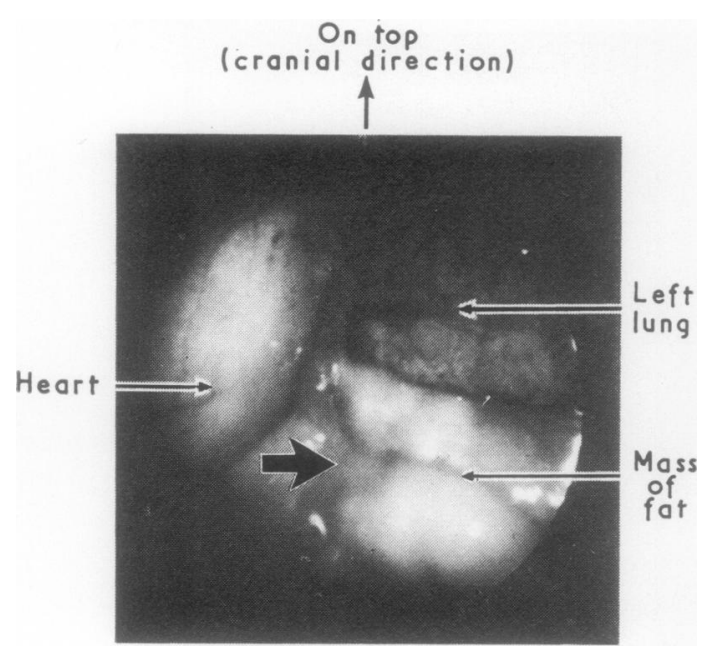

FIG. 3. Thoracoscopic picture of the mass of fat tissue (arrow) adjacent to the heart (left) and the (collapsed) left lung (top right).

corticosteroid therapy. One likely case was discovered and in four patients we found radiographic abnormalities suggestive of intrathoracic lipomatosis-mediastinal widening, prominent epicardial fat pads, or both. All the patients showed a marked Cushingoid appearance.

\section{DISCUSSION}

Although paracardiac lipomatosis has been noted in the obese (Holt, 1947), we were unable to find any report of intrathoracic lipomatosis in Cushing's syndrome. Lipomatosis was suspected in the present case because of the associated Cushing's syndrome, the lack of other symptoms, the symmetrical localization of the abnormal shadows on the chest radiographs, and the additional radiographic abnormalities-thickening of the thoracic $\triangle$ wall and mediastinal widening. As mentioned in के earlier reports (Bodman and Condemi, 1967 ; $\vec{\circ}$ Teates, 1970), the disappearance of the abnormalities when cortiscosteroids are withdrawn also seems to support this diagnosis. However, the possibility of a malignancy, in a patient on immunosuppressive therapy, made further investigation desirable.

Knowledge of this benign abnormality may prevent unnecessary investigation and even surgical exploration.

\section{REFERENCES}

Bodman, S. F., and Condemi, J. J. (1967). Mediastinal widening in iatrogenic Cushing's syndrome. Annals of Internal Medicine, 67, 399.

Fraser, R. G., and Paré, J. A. P. (1970). Diagnosis of Diseases of the Chest, vol. 1, p. 558. W. B. Saunders, Philadelphia.

Holt, J. F. (1947). Epipericardial fat shadows in differential diagnosis. Radiology, 48, 472.

Koerner, H. J., and Sun, D. I. C. (1966). Mediastinal lipomatosis secondary to steroid therapy. American Journal of Roentgenology, 98, 461.

Lucena, G. E., Bennett, W. M., and Pierre, R. V. (1966). "Dewlap": a corticosteroid-induced episternal fatty tumor. New England Journal of Medicine, 275, 834.

Price, J. E. Jr., and Rigler, L. G. (1970). Widening of the mediastinum resulting from fat accumulation. Radiology 96, 497.

Santini, L. C., and Williams, J. L. (1971). Mediastinal widening (presumable lipomatosis) in Cushing's syndrome. New England Journal of Medicine, 284, 1357.

Sowerbutts, J. G. (1959). Some uses for presacral oxygen ? insufflation. Journal of the Faculty of Radiologists, 10, 201.

Teates, C. D. (1970). Steroid-induced mediastinal lipomatosis. Radiology, 96, 501. 